\title{
Hot Water Drench Treatments for the Control of Radopholus similis in Rhapis and Fishtail Palms
}

\author{
A.C. Arcinas, B.S. Sipes, A.H. Hara, and M.M.C. Tsang ${ }^{1}$ \\ Department of Plant and Environmental Protection Sciences, University of \\ Hawaii at Manoa, Honolulu, HI 96822
}

Additional index words. burrowing nematode, plant-parasitic nematode, foliage palms, quarantine, Rhapis excelsa, Caryota mitis

\begin{abstract}
Exporters of potted nursery stock face strict quarantine regulations against the burrowing nematode, Radopholus similis. Currently, there are no treatments approved by quarantine authorities to disinfest plants of $\boldsymbol{R}$. similis. Interceptions of the nematode lead to significant economic loss and curtailment of trade, therefore hot-water drench treatments were investigated for quarantine utility. Drenches with $50{ }^{\circ} \mathrm{C}$ water were applied for 10 to 16 minutes to two economically important palm species, rhapis (Rhapis excelsa) and fishtail (Caryota mitis). Plants were inoculated with 5,000 mixed life stages of $R$. similis and allowed to establish for 14 weeks before drench treatments. In rhapis, a moderately good host to $\boldsymbol{R}$. similis, a 16-minute hot water drench had high efficacy, achieving $99.6 \%$ mortality. In fishtail, a poor host, all treatments longer than 10 minutes at $50{ }^{\circ} \mathrm{C}$ eliminated $R$. similis from the plants. Probit regression estimates of the $\mathrm{LT}_{99}$, were 16.9 and 10.3 minutes respectively. However $\chi^{2}$ goodness-of-fit tests were significant $\left(\chi^{2}=21.136, \mathrm{df}=3, p<0.0001\right)$ for rhapis. Since most observed values were between the $95 \%$ fiducial limits, this suggests that the large $\chi^{2}$ value was caused by variability in response or insufficient repetitions rather than an inappropriate model. A $\chi^{2}$ statistic could not be computed for fishtail because poor host status led to variances that were nearly equal to zero. The high efficacy of hot water drenches for the control of $\boldsymbol{R}$. similis is approaching the Probit 9 standard of $99.9968 \%$ mortality required for approval as a quarantine treatment.
\end{abstract}

Exporters of potted nursery stock face strict quarantine regulations against the burrowing nematode, Radopholus similis. This nematode is a restricted pest in 55 countries including the European Union, Korea, Japan, Taiwan, and by several states in the United States (CAB International, 2002). Currently, there are no treatments approved by quarantine authorities to disinfest plants of $R$. similis. Interceptions of the nematode lead to significant economic loss and curtailment of trade, therefore hot water drench treatments were investigated for quarantine utility.

\section{Materials and Method}

Hot water drenches with $50{ }^{\circ} \mathrm{C}$ water were applied for 10 to 16 min to two economically important palm species, rhapis (Rhapis excelsa) and fishtail (Caryota mitis) (Tsang et al., 2001).

This paper is a portion of a MS thesis submitted by A.C. Arcinas. We thank Christopher Jacobsen and and Ryan Kaneko for their technical assistance and Big Island Plant and Foliage, Inc. (Hilo, Hawaii) and California and Hawaii Nursery (Papaikou, Hawaii) for providing the plants used in this study. This research was funded in part by the U.S. Department of Agriculture under CSREES Special Grant 200234135-12724, managed by the Tropical and Subtropical Agriculture Research (T-STAR), Pacific Basin Admintrive Group (PBAG).ThisistheUniv of Hawaii at Manoa, College of Tropical Agriculture and Human Resources journal series 4659. ${ }^{1}$ College of Agriculture, Forestry, Natural Resource Management, University of Hawaii at Hilo, Hilo, HI 96720.
A)

Two-year-old rhapis palms propagated from stolons and maintained in a $75 \%$ shadehouse and four-year-old fishtail palms propagated from seed and maintained in full sunlight were obtained from commercial nurseries. Rhapis and fishtail palms were planted in $1.3 \mathrm{~cm}$ crushed volcanic cinder and sphagnum peat moss (No. 4 Sunshine Mix, Sun Gro Horticulture, Canada) in a $60 \%: 40 \%$ by weight ratio of cinder to peat in $21-\mathrm{cm}$-diameter plastic pots and 30-cm-diameter plastic pots, respectively. All plants were moved to disinfected $75 \%$ shadehouse benches, inoculated with 5,000 mixed life stages of $R$. similis, and allowed to establish for 14-weeks before drench treatments. Radopholus simlis inoculum was cultured on sterile alfalfa callus tissue, extracted using Baermann funnels, counted, suspended in water at a known population density, and applied to soil surface of potted plants (Ko et al., 1996).

Forty rhapis plants were randomly assigned to the exposure times of $0,10,12,14$, or $16 \mathrm{~min}$ at $50{ }^{\circ} \mathrm{C}$, and 32 fishtail palms were treated at $50{ }^{\circ} \mathrm{C}$ for $0,10,13$, or $16 \mathrm{~min}$. Each exposure was replicated in eight plants. Hot water drenches were applied using a 340-L hot water reservoir, water circulation pump and hoses, thermostatically controlled valve and monitoring unit (Tsang et al., 2001). Hot water drenches were applied to four plants simultaneously. Water temperature was maintained in the tank to within $\pm 0.5^{\circ} \mathrm{C}$ of target temperature. The system was optimized to provid a rapid and uniform rise to target tem-

\section{Rhapis}

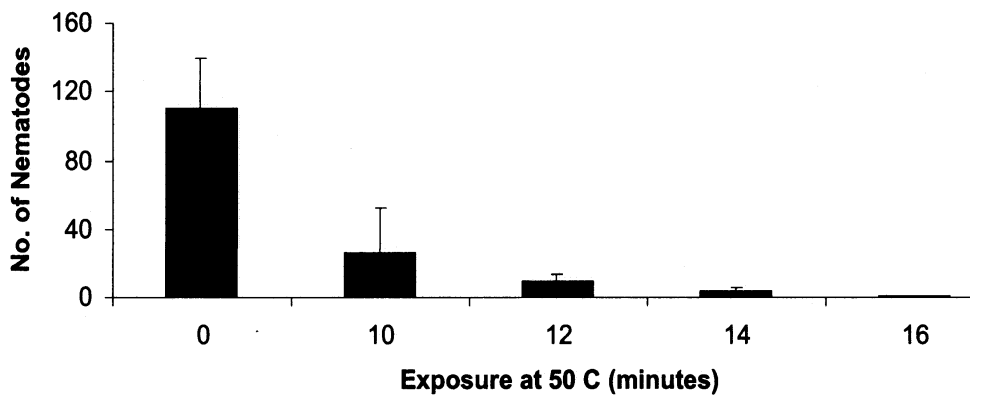

B)

Fishtail

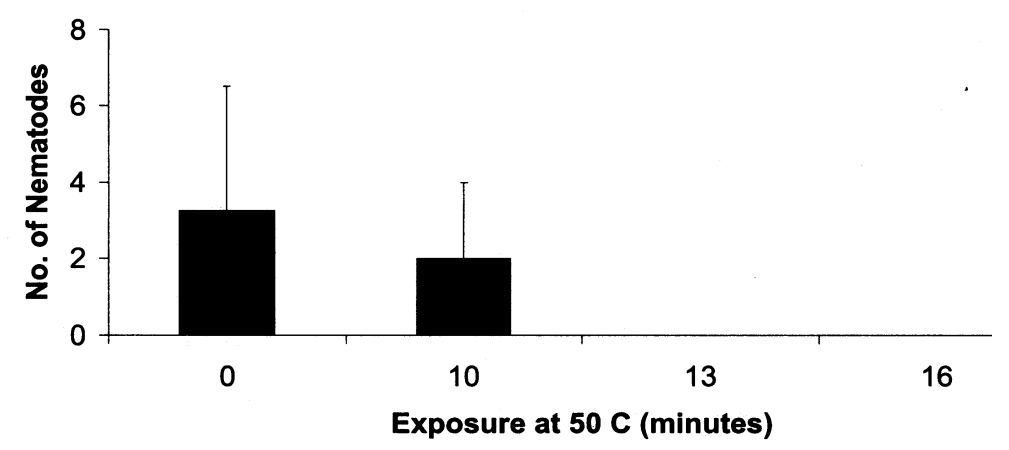

Fig. 1. Mean number of Radopholus similis detected by bag extraction in rhapis (A) and fishtail (B) week after application of hot water drench treatment at $50{ }^{\circ} \mathrm{C}$. Each bar is a mean of eight replications. Vertical bars represent standard error $(\mathrm{n}=8)$. 
perature throughout the potting media. After treatment, all plants were immediately cooled with an ambient $25^{\circ} \mathrm{C}$ water drench using a manifold assembly with four hose fittings, for half of the treatment time.

Plants were assayed for nematode survivors $7 \mathrm{~d}$ later. Shoots were discarded and roots were separated from the media and rinsed. Roots were chopped in 1- to 2-cm pieces and fresh weight was recorded. The root pieces were placed in a $60 \times 20 \times 28$-cm gusseted polyethylene bag and water added to cover half of the tissue. Bags were maintained at $25^{\circ} \mathrm{C}$ in the dark for $7 \mathrm{~d}$. After the incubation, water and root pieces were poured over a $20-\mu \mathrm{m}$ mesh screen to collect nematodes. Samples were subjected to a sugar density gradient and centrifuged to separate nematodes from fine soil and root particles (Barker, 1985).

Statistical analysis consisted of a one-way analysis of variance for exposure treatments. Arcsine transformation of percentage mortality was used to adjust for nonnormal distribution of data. Orthogonal single degree of freedom contrasts were used to identify differences among treatments.

\section{Results}

A positive relationship between exposure to hot water and mortality of $R$. similis was documented in both palms (Fig. 1) Control rhapis and fishtail plants contained an average 110 and 7 mixed life stages of $R$. similis per pot, respectively (Fig. 1). Orthogonal contrasts detected differences between control and all hot water treatments for rhapis $(\mathrm{F}=47.14, P$ $<0.01$ ), but not among the treatments, due to within treatment variance. The 16-min drench treatment had the highest efficacy and reduced $R$. similis populations by $99.6 \%$ compared to the mean of the control treatment, following a maximum likelihood estimate of the starting population (Wadley, 1949). Only one rhapis replication out of eight contained $R$. similis after a 16-min exposure. In fishtail, $R$. similis were only recovered from 0 - and 10-min treatments. Poor host status of fishtail to $R$. similis was confirmed (Goo and Sipes, 1999).

In fisthtail, analysis of variance from bag extraction data detected no difference among treatments $(P=0.48)$. Complete control was observed in all replications from the 13- and 16-min treatments (Fig. 1)

\section{Discussion}

Quarantine protocols accepted by the USDA are based the probit 9 (99.9968\% mortality) security level, which equates to 32 survivors out of a million treated individuals. The observed mortality of $R$. similis from the longer exposure treatments in this study are within an acceptable range to merit furthe investigation into hot water drenches as a possible quarantine treatment.

\section{Literature Cited}

Barker, K.R. 1985. Sampling nematode communities, p. 19-35. In: K.R. Barker, C.C. Carter, and J.N. Sasser (eds.). An advanced treatise on Meloidogyne. vol. 2: Methodology. N.C. State Univ, Graphics, Raleigh.

CAB International. 2002. Radopholus similis In: Crop protection compendium, global module, 4 th ed. CAB Intl., Wallingford, U.K. <http://www. cabicompendium.org/cpc /datasheet>.

Goo, M.Y.C. and B.S. Sipes. 1997. Host preference of Radopholus citrophilus from Hawaiian Anthurium among selected tropical ornamentals. HortScience 32:1237-1238.

Ko, M.P., D.P. Schmitt, and B.S. Sipes. 1996. Axenizing and culturting endomigratory plant-parasitic nematodes using Pluronic F127, including its effects on population dynamics of Pratylenchus penetrans. J. Nematol. 28:115-123.

Tsang, M.M.C.,A.H. Hara, and B.S. Sipes. 2001. Hot water drenching system for disinfesting roots and media of potted plants of burrowing nematodes. Appl. Eng. Agr. 17:533-538

Wadley, F.M. 1949. Dosage-mortality correlation with number treated estimated from a parallel sample. Ann. Appl. Biol. 36:196-202. 